Contents list avaliable at Directory of Open Access Journals (DOAJ)
Aulad : Journal On Early Childhood
Vol 3 No 32020, Pages $121-125$
ISSN : 2655-4798 (Printed); 2655-433X (Online)
Journal Homepage: https://aulad.org/index.php/aulad

\title{
Pengembangan Media Miniature City Letteruntuk Meningkatkan Kemampuan Menulis Anak Usia 4-5 Tahun
}

\author{
Sri Wahyuni ${ }^{1 凶}$, Rita Kurnia², Zulkifli ${ }^{3}$ \\ Pendidikan Guru Pendidikan Anak Usia Dini, Universitas Riau \\ DOI: 10.31004/aulad.v3i3.78
}

Corresponding Author [sriw2987@gmail.com]

\begin{tabular}{ll}
\hline Article Info & Abstrak \\
\hline Keywords: & Penelitian ini bertujuan untuk mengetahui kelayakan media Miniature City Letter \\
Gross Motor & untuk meningkatkan kemampuan menulis pada anak usia 4-5 tahun yang diuji oleh \\
Preschool & beberapa validator. Penelitian ini menggunakan metode penelitian pengembangan \\
Development & Research and Development dengan model ADDIE. Penelitian dilakukan di TK \\
Gender & Marfu'ah Pangkalan Kerinci. Uji kelayakan dilakukan 5 orang guru PAUD dan 2 \\
Skill & orang ahli media. Lembar validasi dijadikan sebagai teknik pengumpulan data, data \\
& yang didapatkan kemudian diolah. Dapat disimpulkan bahwa terdapat \\
pengembangan media Miniature City Lettersebelum dan sesudah dilakukannya uji & kelayakn oleh validator. Berdasarkan hasil lembar validasi oleh beberapa validator \\
& dapat diperoleh bahwa pengembangan media Miniature City Letter untuk \\
& meningkatkan kemampuan menulis anak usia 4-5 tahun dapat digunakan oleh \\
& PAUD dengan kriteris "Sangat Layak".
\end{tabular}

\section{Abstract}

Kata kunci:

Motorik Kasar

Prasekolah

Perkembangan

Gender

Keterampilan

\begin{abstract}
This study aims to determine the feasibility of Miniature City Letter media to improve writing skills in children aged $4-5$ years tested by several validators. This study uses a Research and Development development research method with the ADDIE model. The research was conducted at TK Marfu'ah Pangkalan Kerinci. The feasibility test was carried out by 5 PAUD teachers and 2 media experts. The validation sheet is used as a data collection technique, the data obtained is then processed. It can be concluded that there was a development of Miniature City Letter media before and after the validator test was carried out. Based on the results of validation sheets by several validators, it can be found that the development of Miniature City Letter media to improve the writing skills of children aged 4-5 years can be used by PAUD with the criterion of "Very Appropriate".
\end{abstract}

\section{PENDAHULUAN}

Anak usia dini merupakan kelompok usia yang berada dalam proses perkembangan unik, karena proses perkembangannya terjadi bersama dengan golden age, yang merupakan waktu paling tepat untuk memberikan bekal yang kuat kepada anak. Pada tahap emas ini, para pendidik khususnya orangtua perlu memberikan stimulasi dan pendidikan terbaik untuk tumbuh kembang anak (Islamiah et al., 2019). Dengan demikian anak-anak pada masa usia dini memerlukan berbagai layanan dan bantuan orang dewasa, dari kebutuhan jasmani sampai rohani.

Dalam Undang-Undang Nomor 20 Tahun 2003 tentang Sistem Pendidikan Nasional pasal 1 ayat 14 dinyatakan bahwa "Pendidikan anak usia dini adalah suatu upaya pembinaan yang ditujukan kepada anak sejak lahir sampai dengan usia enam tahun yang dilakukan melalui pemberian rangsangan pendidikan untuk membantu pertumbuhan dan perkembangan jasmani dan rohani agar anak memiliki kesiapan dalam memasuki pendidikan lebih 
lanjut baik dalam jalur pendidikan formal maupun non formal" (Sisdiknas, 2003). Untuk itu pendidikan pada anak usia dini sangat diperlukan untuk menghadapi masa depan anak dengan bantuan guru dan orangtua baik di sekolah maupun di rumah (Kementerian Kesehatan Republik Indonesia, 2016).

Salah satu kesiapan yang semestinya dicapai oleh anak usia dini adalah kemampuan keaksaraan. Kemampuan keaksaraan pada anak usia dini merupakan kemampuan awal dan fondasi dasar yang diperlukan anak agar mampu belajar menulis, membaca, dan berhitung (Listriani et al., 2020). Belajar menulis untuk anak perlu diajarkan sejak dini. Walaupun keterampilan menulis bukanlah aspek yang ditekankan di usia prasekolah, bukan berarti anak-anak usia 4-5 tahun tidak boleh diajarkan untuk menulis. Hal terpenting adalah porsinya tidak melebihi kemampuan anak. Anak juga harus merasa senang dan tidak terpaksa ketika diajarkan untuk menulis. Pembelajaran menulis, diajarkan pada tahapan perkembangan anak dengan pendekatan bermain melalui belajar dan belajar melalui bermain yang dapat mendukung semua segi aspek perkembangan anak walaupun pada point utamanya adalah pembelajaran menulis (Marlisa, 2016).

Kemampuan menulis merupakan salah satu kemampuan yang dikembangkan oleh guru dan orangtua pada anak usia dini. Kemampuan menulis dapat digunakan untuk mengekspresikan gagasan, perasaan, dan pengalaman dengan menggunakan tulisan yang dapat dipahami pembaca dan sesuai dengan tujuan yang dimaksud oleh penulisnya. (Kurnia, 2009). Sedangkan pada kemampuan menulis, anak memerlukan yaitu kemampuan meniru bentuk dan kemampuan menggerakkan alat tulis (Kurnia, 2018). Kemampuan menulis bermanfaat bagi anak dalam upaya persiapan masuk ke jenjang sekolah dasar (Oktovia, 2018).

Dalam meningkatkan kemampuan menulis anak usia dini seorang pendidik harus dapat mengembangkan melalui media pembelajaran. Media pembelajaran merupakan alat (perantara) dalam memberikan materi kepada anak dalam proses pembelajaran. Media pembelajaran yang digunakan di PAUD biasanya berupa media cetak (majalah, buku cerita), alat permainan edukatif (APE), audio visual, poster, dan papan flanel. Namun, pada kenyataannya penerapan media dalam pembelajaran kurang diterapkan oleh pendidik dalam mengembangkan kemampuan menulis anak.

Berdasarkan hasil observasi di beberapa Taman Kanak-Kanak di Kecamatan Tenayan Raya media pembelajaran yang tersedia beberapa buku, LKA, kartu huruf hitam putih untuk mereka belajar dalam menulis, sehingga dalam mengembangkan kemampuan menulis anak usia dini sangat kurang optimal. Kemudian dalam kegiatan tanya jawab anak terlihat tidak menjawab dan cenderung sangat diam ketika kegiatan pembelajaran berlangsung.

Berdasarkan uraian tersebut peneliti ingin melakukan penelitian dan pengembangan sebuah produk yaitu Miniature City Letter. Miniature City Letter adalah suatu media yang didesain secara unik dan kreatif dengan kebutuhan dari proses pembelajaran yang akan dikenalkan kepada anak. Seperti mengenalkan huruf-huruf kemudian membuat rancangan dimana anak akan melakukan kegiatan menulis dengan tahapan-tahapan menulis sesuai dengan kemampuan menulis anak usia 4-5 tahun. Sari et al. (2013) berhasil meningkatkan kemampuan mengenal huruf abjad dengan menggunakan kartu huruf. Pada penelitian ini penulis mengembangkan kartu huruf dengan Miniature City Letter. Pengembangan Miniature City Letter yang dikembangkan oleh peneliti yakni pada huruf abjad pada media Miniature City Letter akan terdapat berbagai tahapan menulis yang akan anak lakukan di dalam media ini dengan kombinasi warna dan desain yang menarik akan menceritakan situasi sesuai apa yang mereka lihat pada media tersebut.

Berdasarkan latar belakang diatas, maka peneliti melakukan penelitian dan pengembangan dengan judul "Pengembangan media Miniature City Letter untuk meningkatkan kemampuan menulis anak usia 4-5 tahun".

\section{METODE PENELITIAN}

Model penelitian ini, mengadaptasi pada model pengembangan ADDIE, model ini terdiri atas 5 tahap yang meliputi analisis (analysis), perencanaan (design), pengembangan (development), pelaksanaan (implementation), dan pengujian (evaluation). Tahap implementation dan evaluation tidak dilakukan karena keterbatasan dalam hal waktu dan biaya (Gambar 1).

Instrumen pengumpulan data yang digunakan dalam penelitian ini adalah lembar validasi. Lembar validasi dalam penelitian ini adalah lembaran yang digunakan untuk memvalidasi produk yang dikembangkan. Tujuan pengisian lembar validasi adalah untuk menguji kelayakan media pembelajaran Miniature City Letter yang dikembangkan.

Data penelitian dikumpulkan dengan mengisi lembar validasi pengembangan media. Data diperoleh dari hasil validasi tiap-tiap validator untuk mengetahui hasil dari pengembangan media pembelajaran. Untuk menilai validitas sebagai narasumber yang dianggap ahli dalam bidang media pembelajaran yaitu terdiri dari 7 orang validator, yang terdiri dari satu orang ahli media, satu orang ahli materi, dan lima orang ahli pendidik.

Teknik analisis data yang digunakan adalah analisis deskriptif yang mendeskripsikan kelayakan media pembelajaran Miniature City letter yang dikembangkan dengan menggunakan metode skala Likert. Skala Likert adalah suatu skala psikometrik yang digunakan dalam kuisioner, mengungkap sikap dan pendapat seseorang terhadap suatu fenomena. 


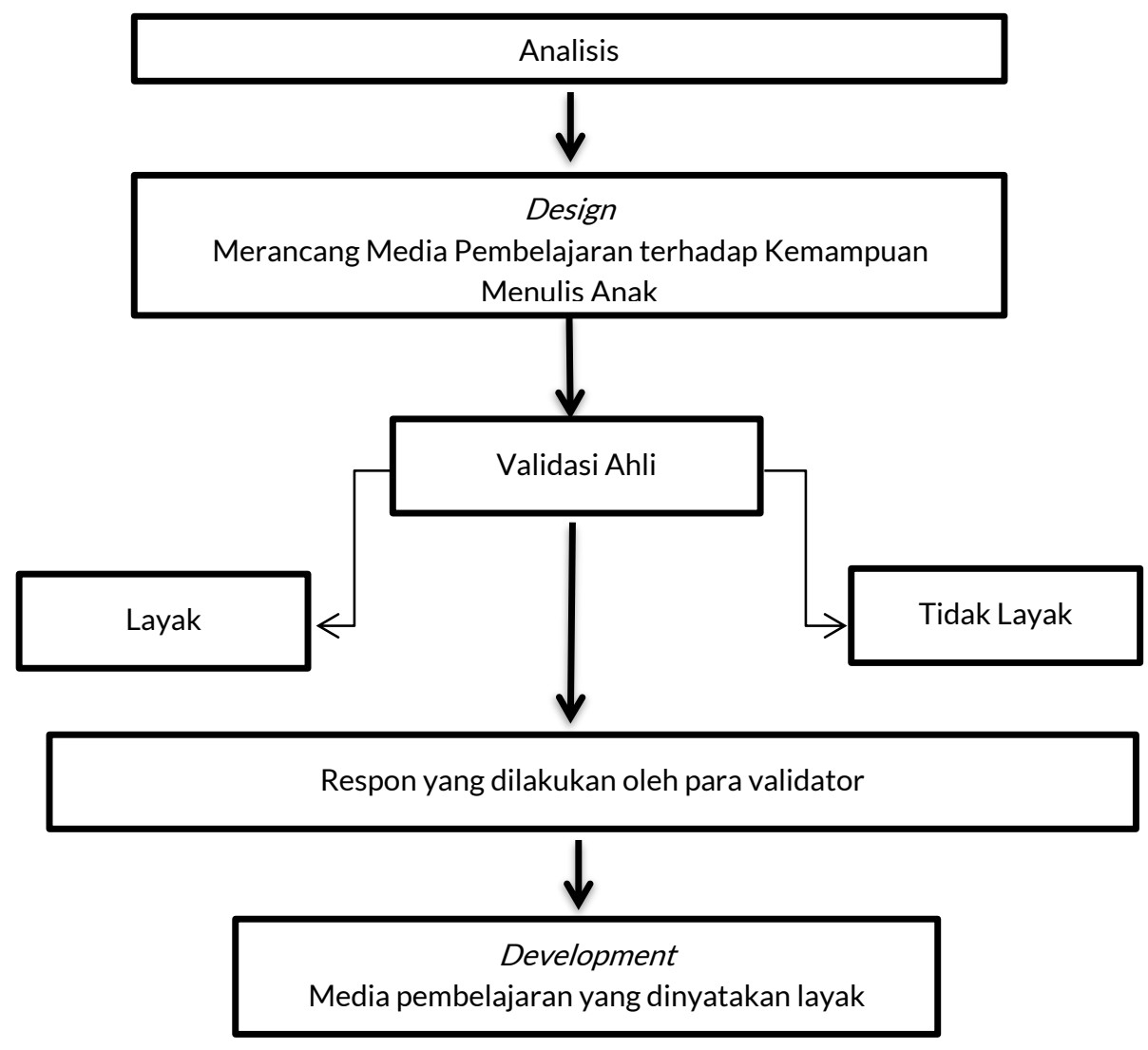

Gambar 1. Prosedur penelitian

\section{HASIL DAN PEMBAHASAN}

Penilaian validator ahli media terhadap media pembelajaran Miniature City letter terhadap kemampuan menulis anak usia 4-5 tahun meliputi 5 aspek yaitu aspek fisik, gambar, warna, tulisan dan pemakaian. Hasil validasi ahli media dapat dilihat pada tabel 1.

Tabel 1. Hasil Validasi Ahli Media

\begin{tabular}{|c|c|c|c|}
\hline No & Aspek & Persentasi Kelayakan (\%) & Tingkat Kelayakan \\
\hline 1. & Fisik & 87,5 & Sangat layak \\
\hline 2. & Gambar & 87,5 & Sangat layak \\
\hline 3. & Warna & 87,5 & Sangat layak \\
\hline 4. & Tulisan & 91,6 & Sangat layak \\
\hline 5. & Pemakaian & 91,6 & Sangat layak \\
\hline \multicolumn{2}{|c|}{ Rata-rata validasi media } & $\mathbf{8 9 , 1 4}$ & Sangat layak \\
\hline
\end{tabular}

Masukan dan saran dari validator ahli media dianalisis oleh peneliti yaitu terdapat pada kegiatan menulis anak. Dari tahapan cara menggunakan media guru yang menentukan kegiatan menulis, jadi kegiatan pembelajaran berorientasi pada guru. Sebaiknya anak lah yang menentukan sendiri memilih bagaimana dan serta termasuk mau menulis apa. Kemudian sebaiknya ada penjelasan berapa tinggi meja dan berapa ukuran panjang, lebar masingmasing dari jenis kegiatan main satu dengan yang lain. Mengingat salah satu prinsip pembelajaran termasuk menggunakan media adalah kesesuaian dengan perkembangan anak.

Penilaian validator terhadap media Miniature City letter meliputi 2 aspek yaitu aspek segi edukatif dan penyajian. Hasil valiadasi ahli materi dapat dilihat pada tabel 2.

Tabel 2. Hasil Validasi Ahli Materi

\begin{tabular}{|c|c|c|c|}
\hline No & Aspek & Persentasi Kelayakan (\%) & Tingkat Kelayakan \\
\hline 1. & Segi Edukatif & 92,85 & Sangat layak \\
\hline 2. & Penyajian & 93,75 & Sangat layak \\
\hline \multicolumn{2}{|c|}{ Rata-rata validasi materi } & $\mathbf{9 3 , 3}$ & Sangat layak \\
\hline
\end{tabular}

Sumber: Data Peneliti 
Menurut penilaian dari validator ahli materi dapat dilihat memiliki tingkat kelayakan sangat layak. Secara keseluruhan tingkat kelayakan untuk media pembelajaran Miniature City letteroleh ahli materi adalah sangat layak tanpa revisi dengan rata-rata persentase $93,3 \%$.

Lembar validasi guru terdiri atas dua aspek yaitu aspek materi dan penyajian. Masukan dan saran dari validator guru dianalisis oleh peneliti untuk mengadakan perbaikan pada media Miniature City Letter yang dikembangkan. Berdasarkan penilaian dari validator oleh guru PAUD dapat dilihat memiliki tingkat kelayakan yaitu sangat layak dengan persentase kelayakan 94,15\%. Adapun rincian dari rata-rata persentase hasil guru PAUD oleh Ibu Asianti, S.Pd memiliki rata-rata persentase kelayakan 93,75\% (sangat layak), untuk hasil validasi oleh Ibu Kurniawaty, S.Pd memiliki tingkat kelayakan yaitu sangat layak dengan persentase kelayakan $96,87 \%$.

Selanjutnya hasil rata-rata persentase oleh Ibu Lilis Suryani, S.Pd memiliki rata-rata persentase kelayakan dari media yang dikembangkan adalah 93,75\% (sangat layak). Untuk hasil validasi oleh Ibu Asmita Susanti, S.Pd memiliki tingkat kelayakan yaitu sangat layak dengan persentase kelayakan 93,75\% kemudian untuk hasil validasi oleh Ibu Herliani, S.Pd memiliki rata-rata persentase kelayakan media yang dikembangkan adalah 92,70\% (sangat layak). Secara keseluruhan tingkat kelayakan untuk media pembelajaran Miniature City Letteryang di validasi oleh guru PAUD adalah sangat layak di uji cobakan tanpa adanya revisi.

\section{Pembahasan}

Penelitian ini dilakukan di TK Marfu'ah Pangkalan Kerinci. Penelitian ini menghasilkan media pembelajaran Miniature City Letter terhadap kemampuan menulis anak usia 4-5 tahun. Peneliti memilih mengembangkan media pembelajaran Miniature City Letter, berdasarkan analisis kebutuhan dari hasil observasi. Materi yang terdapat di dalam media pembelajaran sesuai dengan kurikulum yang mengacu pada Peraturan Menteri Pendidikan dan Kebudayaan Republik Indonesia Nomor 137 Tahun 2014.

Uraian tentang kelayakan media pembelajaran Miniature City Letteryang meliputi validasi oleh ahli media, ahli materi dan guru PAUD. Kevalidan media pembelajaran ditentukan dengan menghitung rata-rata nilai aspek untuk tiap-tiap validator.

Masukan dan saran dari validator ahli pendidik adalah (1) pada materi kegiatan menulis sebaiknya guru memberikan petunjuk berupa titik-titik yang membentuk sebuah huruf mengingat usia yang dikembangkan adalah usia 4-5 tahun. Peneliti melakukan perbaikan yaitu membuat titik-titik untuk mempermudah anak melakukan kegiatan menulis. Sejalan dengan penelitian Atabik \& Burhanuddin (2015) mengatakan bahwa tolok ukur pembelajaran PAUD hendaknya bertumpu pada hal-hal atau kegiatan yang telah mampu dikerjakan anak. Selanjutnya dalam penelitian Nuraeni (2019) menyatakan bahwa karakteristik anak sebagai peserta didik baik usia maupun kemampuannya, setiap anak memiliki karakteristik dan kemampuan yang berbeda-beda sehingga guru terlebih dahulu peka membuat kegiatan pembelajaran sesuai dengan usia dan kemampuan anak agar tidak terjadi suatu pemaksaan terhadap kemampuan anak.

Penelitian terdahulu tentang kemampuan menulis yang dilakukan oleh Hidayati (2020) dapat dilihat dari tingkat kelayakan media pembelajaran berbasis buku kata bergambar oleh ahli media, pengembangan media dapat diperoleh rata-rata keseluruhan $80,6 \%$ dengan kategori sangat layak. Ahli materi diperoleh dengan rata-rata $98 \%$ kategori sangat layak. Selanjutnya penelitian Maghfiroh (2017) mengenai pengembangan buku panduan membaca dan menulis permulaan dengan media Kartu Huruf menggunakan metode SAS, menunjukkan bahwa penilaian ahli media dan ahli materi termasuk dalam kriteria sangat layak untuk digunakan dan mempunyai nilai rata-rata dari uji kelayakan dengan persentase $100 \%$ sangat layak.

Berdasarkan uraian diatas dapat disimpulkan bahwa Pengembangan Media Miniature City Letterterhadap Kemampuan Menulis Anak Usia 4-5 Tahun dengan rata-rata ahli media yaitu 89,14\% sangat layak, oleh ahli materi 93,3\% dengan kategori sangat layak digunakan.

\section{SIMPULAN}

Pengembangan media Miniature City Letteruntuk meningkatkan kemampuan menulis anak usia 4-5 tahun sangat layak digunakan untuk PAUD. Terdapat pengembangan media setelah dilakukan uji kelayakan oleh beberapa validator dengan rata-rata oleh ahli guru PAUD sebesar $94,15 \%$, ahli media sebesar $98,14 \%$ dan ahli materi diperoleh sebesar 93,5\% dengan kriteria kelayakan yaitu sangat layak. Hasil penelitian ini dapat dijadikan acuan dalam melakukan penelitian sebelumnya agar peneliti lainnya dapat mencari alternatif dalam menghadapi permasalahan yang ada dengan pendekatan, metode, teknik, media atau strategi pembelajaran yang efektif.

\section{DAFTAR PUSTAKA}

Atabik, A., \& Burhanuddin, A. (2015). Prinsip dan Metode Pendidikan Anak Usia Dini. Thufula: Jurnal Inovasi Pendidikan Guru Raudhatul Atfal, 3(2).

Hidayati, A. (2020). Pengembangan Bukatber (Buku Kata Bergambar) Berbasis Android Untuk Meningkatkan Kemampuan Menulis Anak. Journal for Lesson and Learning Studies Vol., 3(2).

Islamiah, F., Fridani, L., \& Supena, A. (2019). Konsep Pendidikan Hafidz Qur'an pada Anak Usia Dini. Jurnal Obsesi : Jurnal Pendidikan Anak Usia Dini, 3(1), 30. https://doi.org/10.31004/obsesi.v3i1.132 
Kementerian Kesehatan Republik Indonesia. (2016). Pedoman Pelaksanaan Stimulasi, Deteksi dan Intervensi Dini Tumbuh Kembang Anak. Summary for Policymakers.

Kurnia, R. (2009). Metodologi pengembangan bahasa anak usia dini. Pekanbaru: Cendikia Insani.

Kurnia, R. (2018). Pengembangan Kemampuan Menulis Anak Usia Dini Dengan Tema Alam Semesta. Educhild, 72), 95-101.

Listriani, A., Hapidin, H., \& Sumadi, T. (2020). Kemampuan Keaksaraan Anak Usia 5-6 Tahun dalam Penerapan Metode Spalding di TK Quantum Indonesia. Jurnal Obsesi : Jurnal Pendidikan Anak Usia Dini, 5(1), 591. https://doi.org/10.31004/obsesi.v5i1.680

Maghfiroh, S. (2017). Pengembangan Buku Panduan Membaca dan Menulis Permulaan dengan Media Kartu Huruf Menggunakan Metode SAS. Universitas Negeri Semarang.

Marlisa, L. (2016). Tuntutan Calistung pada Anak Usia Dini. Jurnal. Jurnal IImiah Tumbuh Kembang Anak Usia Dini, 1(3), 25-38.

Nuraeni, L. (2019). Pengembangan Media Pembelajaran Busy Book Dalam Meningkatkan Kemampuan Bahasa Anak Usia Dini Di Play Group Bina Balita Way Halim Bandar Lampung. Universitas Islam Negeri Raden Intan Lampung.

Oktovia, B. (2018). Pengaruh Kegiatan Finger Painting Terhadap Kemampuan Menulis Anak Di Tkn Pembina Kabupaten Tanah Datar. IAIN Batusangkar. http://repo.iainbatusangkar.ac.id/xmlui/handle/123456789/11588

Sari, N. S., Aunurrahman, \& Sutarmanto. (2013). Analisis Penggunaan Media Kartu Huruf dalam Pembelajaran Pengenalan Huruf Abjad TK Pertiwi II Pontianak. Jurnal Pendidikan Dan Pembelajaran Khatulistiwa.

Sisdiknas. (2003). Undang-undang Republik Indonesia Tentang Sistem Pendidikan Nasional Nomor 20 Tahun 2003. 